\title{
Predicting the amount of ethanol consumed per bout from schedule of access to ethanol
}

\author{
HENRY MARCUCELLA \\ Boston University, Boston, Massachusetts
}

\begin{abstract}
The present paper suggests that the difficulty in inducing animals to orally self-administer quantities of ethanol sufficient to produce dependence is related to the schedule of ethanol access. If the variables that control the various patterns of ethanol consumption can be identified, then the patterns of ethanol consumption leading to excessive intake and the development of dependence will be able to be identified and generated experimentally. Evidence is presented which shows that the amount of ethanol consumed per bout, the daily frequency of ethanol bouts, as well as the total amount of ethanol consumed, is a function of the frequency of ethanol access periods, feeding condition, ethanol concentration, and the temporal proximity of ethanol access periods.
\end{abstract}

In the attempt to discover the variables responsible for the development of human alcoholism, many investigators have attempted to induce excessive ethanol consumption in nonhuman organisms. Modeling pathology in animals has proved enormously useful in other areas of science and medicine, and there is little reason to believe, a priori, that an animal model of human alcoholism would not contribute to our understanding of human alcoholism. Not only could the many presumed psychological causes of alcoholism, such as stress, for example, be examined under controlled conditions, but also treatment techniques having the potential to decrease consumption could be designed and tested. An adequate animal model would also help determine the physiological effects of prolonged ethanol consumption uncontaminated by the possible nutritional and other health-care deficiencies usually observed in human alcoholics.

Unfortunately, nonhuman organisms do not spontaneously consume ethanol in amounts that readily lead to intoxication or the development of physical dependence. The failure of procedures to induce oral consumption of ethanol for its pharmacological effect (Lester, 1966; Mardones, 1960; Meisch, 1977; Mello, 1973; Myers \& Veale, 1972; Wallgren \& Barry, 1970; Wayner \& Greenberg, 1972) has been attributed to either the aversive taste of ethanol (Altshuler, Weaver, \& Phillips, 1975; Mello, 1973) or to the delay between ingestion and the onset of its pharmacological effect (Lester \& Freed, 1973; Mello, 1973). Yet failure to consume because of taste and delay

Presented at the Seventh Harvard Symposium on Quantitative Analyses of Behavior: Biological Determinants, Harvard University, June 8-9, 1984. Much of the work reported here was supported by the National Institute of Alcoholism and Alcohol Abuse. I thank Ilse Munro and James S. MacDonall for their considerable intellectual contribution to the research effort, and J. Michael Harrison for his helpful comments on earlier versions of this chapter. Correspondence may be addressed to Henry Marcucella, Department of Psychology, 64 Cummington St., Boston University, Boston, MA 02215. of effect cannot be the complete explanation, for considerable consumption can be induced by presenting ethanol intragastrically (Altshuler, 1980; Altshuler \& Phillips, 1978; Altshuler, Weaver, \& Phillips, 1975) or by a polydipsia procedure and food deprivation (Falk, Samson, \& Winger, 1972)-procedures in which delay and taste factors are inherent features. An alternate view is that the failure to induce oral self-administration is somehow related to a lack of understanding of how the animals' drinking mechanisms work. For example, presenting ethanol intragastrically not only eliminates taste stimuli, but also bypasses the oral ingestion system. The polydipsia procedure, in which food is presented periodically in very small amounts, alters patterns of drinking in general; it is not specific to alcohol (Falk, 1961, 1966a, 1966b, 1967).

The present approach is to develop an animal model of alcoholism within an evolutionary context. The behavior of a particular species evolves within a specific environmental context. Consequently, an understanding of the animal's behavior requires the identification of the particular relations between that behavior and the environment that have been established during the animal's phylogenetic history, as well as an understanding of the extent to which these relations can be modified within its ontogenetic history. For example, the question of how to induce rats to consume large amounts of ethanol is related to an understanding of the behavioral mechanisms involved in the rat's eating and drinking. This behavior has evolved in such a way that it is likely to be under the control of a variety of environmental or situational variables, whose role in determining the amount and patterns of consumption are just beginning to be understood (Weijnen $\&$ Mendelson, 1978). The approach does not assume that the environmental variables controlling excessive consumption will be the same across species. It is highly likely that the set of variables controlling intake of a particular substance will be considerably different for species that have evolved under vastly different conditions. The value 
of the model to the study of human alcoholism is heuristic. The present paper reviews the results of a series of studies that examine how one of these relations between environment and behavior-the effect of conditions of access on patterns of consumption-interacts with ethanol concentration, and feeding condition, to influence the amount of ethanol consumed.

\section{RESTRICTED ACCESS}

Placing constraints on access to alcohol increases consumption. This alcohol deprivation effect (LeMagnen, 1960; Sinclair \& Senter, 1967; Sinclair \& Senter, 1968) occurs after unrestricted access has been interrupted and diminishes within days after unrestricted access is reinstated.

Alternating sessions of access with sessions of nonaccess augments the effect (Amit, Stern, \& Wise, 1970; Pinel \& Huang, 1976; Veale \& Myers, 1969; Wayner \& Greenberg, 1972; Wayner, Greenberg, Carey, \& Nolley, 1971; Wayner et al., 1972; Wise, 1973). For example, Wayner et al. (1972) reported increased ethanol consumption following a restricted-access schedule wherein ethanol was presented for 2 days and withheld for 2 days. But again the increases were not maintained when unrestricted access was introduced (Pinel \& Huang, 1976; Sinclair \& Bender, 1979).

The animals' behavior toward ethanol, a substance unnecessary for survival, when access is restricted may be an example of the tendency of animals to increase their consumption of life-sustaining substances following periods of restricted access (Tagliaferro \& Levitsky, 1982). In addition to increases in total consumption, restricted access also alters the pattern of food and water consumption. Restricting access to food (Collier, Hirsch, \& Hamlin, 1972) or water (Marwine \& Collier, 1979), by requiring the emission of a sequence of responses in order to produce access, increased the amount of food and water consumed per bout. In these consumption studies, bouts were shown to be basic behavioral units of consumption. Animal drinking occurs in periods of rapid licking of consistent duration, followed by much longer periods of no responding (Halpern, 1977).

If the alcohol deprivation effect is part of the same behavioral process of increased consumption following restriction, then ethanol consumption should also occur in distinct bouts, and the amount consumed per bout should be a function of the schedule of access to ethanol. The results of a series of studies conducted in the present laboratory have demonstrated that responding to ethanol does occur in bouts, and that restricting access to specified periods within each 24-h session alters the amount of ethanol consumed per bout, the pattern of these daily bouts of ethanol consumption, and also the total amount consumed per day (MacDonall \& Marcucella, 1979; Marcucella, MacDonall, \& Munro, 1981; Marcucella, Munro, \& MacDonall, 1984).
The subjects of all the experiments to be described were male Sprague-Dawley rats (Holzman and Company) 150 days old at the beginning of the experiment. The subjects were housed in experimental chambers under conditions of controlled temperature $\left(20.0^{\circ}-25.0^{\circ} \mathrm{C}\right)$ and constant illumination, and they were given unrestricted access to water. Sixteen Bussey rat cages served as the experimental chambers (Marcucella et al., 1984). Each cage door was replaced with a clear Plexiglas panel. Two 50-ml glass syringes were suspended vertically from the exterior face of each panel. Each syringe was connected first to a Gilmont capillary valve, then to an Allenair liquid solenoid valve, and finally to a stainless steel drinking spout. Fluid was obtained through a 2-mm-diam opening at the end of the spout. One of the two spouts was attached to the panel in a fixed position, $5 \mathrm{~mm}$ behind a $10-\mathrm{mm}$ opening. The other, controlled by an adjacent motor, could be remotely projected into a similar position or retracted out of reach of the subject. When both spouts were accessible to the subject, they were $45 \mathrm{~mm}$ apart, with a small dim light below the retractable spout illuminated.

Contact with either spout activated a Loveland capacitance-sensitive touch detector that operated the solenoid valve. The rate of flow through the capillary valve and the operation time of the solenoid valve were calibrated to produce a mean daily volume per lick of $0.006 \mathrm{ml}$. In addition, all solenoid valves were operated for $100 \mathrm{msec}$ every hour, independently of the subjects' behavior, in order to prevent the constantly occurring

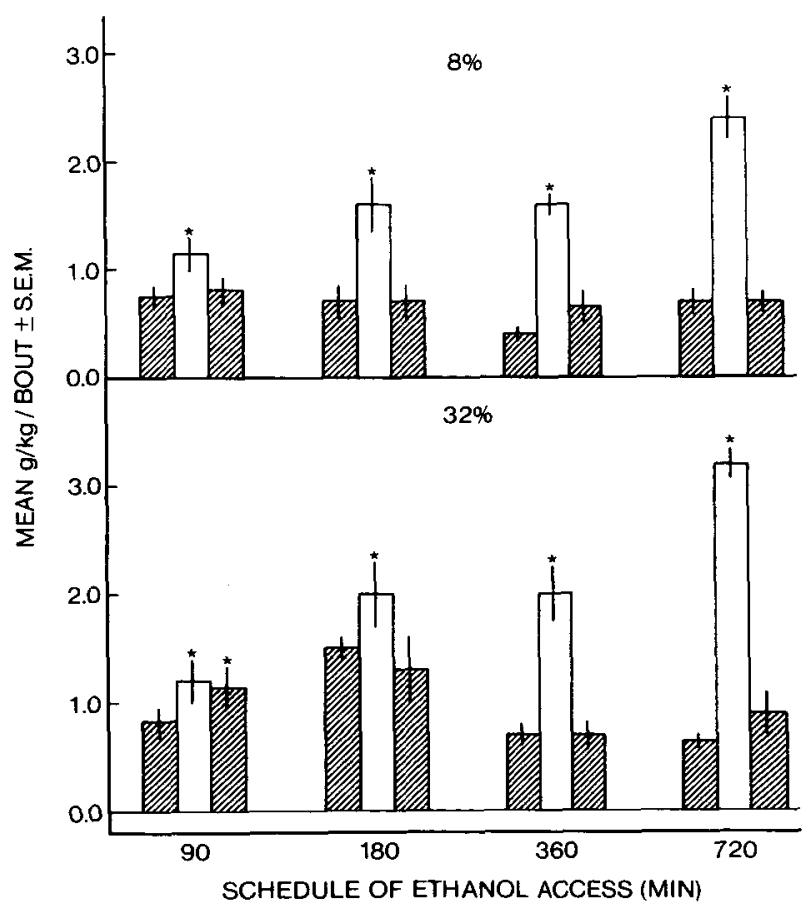

Figure 1. Mean $\mathrm{g} / \mathrm{kg}$ ethanol per bout $\pm \mathrm{SEM}$ during restricted (solid bars) and unrestricted (hatched bars) access (from Marcucella, Munro, \& MacDonall, 1984). 
evaporation at the tube tip from altering the amount of fluid delivered per lick.

A DEC PDP-8E laboratory computer controlled all experimental events and recorded contacts with each spout in 10-min intervals for each 23-h session. The sessions were $23 \mathrm{~h}$ in duration in all the experiments. They began, regardless of condition, at $1700 \mathrm{~h}$, with both water and ethanol spouts available to the subjects as well as the daily food ration present. At $1600 \mathrm{~h}$, all subjects were moved to retaining cages for $1 \mathrm{~h}$. During this period, volume measures, to the nearest $0.5 \mathrm{ml}$, were recorded and corrected for fluid loss due to evaporation and flushing; the subjects were weighed; the ethanol and water syringes were cleaned, flushed, and refilled; and the chambers were cleaned. At $1700 \mathrm{~h}$, all animals were returned to their experimental chambers.

Total session ethanol consumption (grams per kilogram body weight) calculations were based on presession weight and were used, together with 10-min lick totals, to quantify bout size. For example, the amount of ethanol consumed by a $0.500-\mathrm{kg}$ animal in a 1,000 -lick bout is 1,000 licks $\times 0.006 \mathrm{ml} /$ lick $\times 0.32 \mathrm{~g} / \mathrm{ml}$ divided by $0.500 \mathrm{~kg}$ $=3.84 \mathrm{~g} / \mathrm{kg}$. A bout was defined as a period of drinking initiated by 10 or more licks occurring within the same 10-min interval and terminated by a 10 -min period of no responding. Bout frequency and interbout interval (IBI) were also based on this criterion.

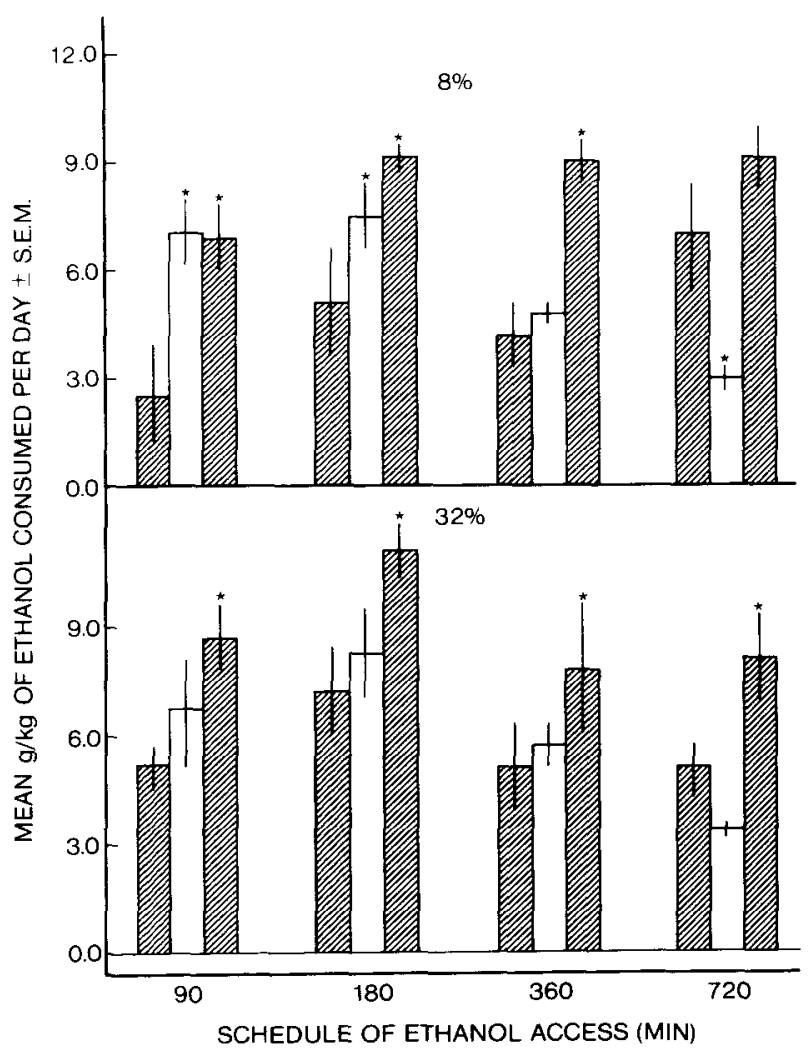

Figure 2. Mean daily ethanol consumption $(g / k g) \pm S E M$ during restricted (solid bars) and unrestricted (hatched bars) access (from Marcucella, Munro, \& MacDonall, 1984).

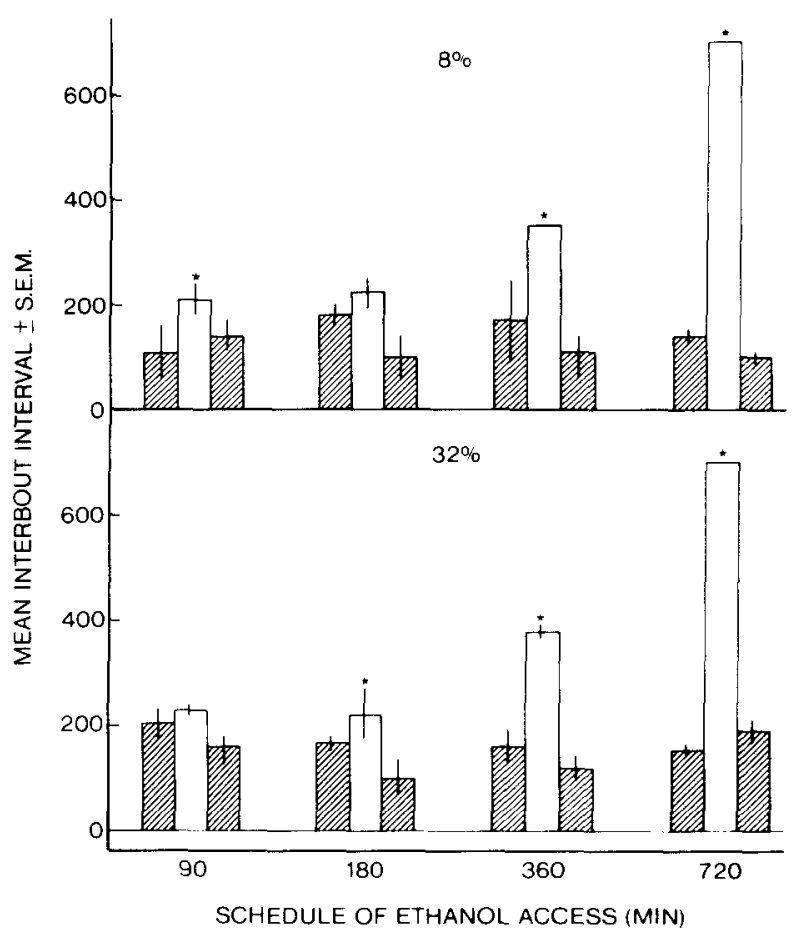

Figure 3. Mean interbout interval (IBI in min) \pm SEM during restricted (solid bars) and unrestricted (hatched bars) access (from Marcucella, Munro, \&MacDonall, 1984).

\section{Schedule of Access and Ethanol Concentration}

The first experiment examined how ethanol concentration and the daily frequency of 20-min ethanol access periods influenced patterns of consumption. A 20-min access period was chosen on the basis of the results of an earlier study (Marcucella et al., 1981) in which $1 \mathrm{~h}$ of access to ethanol was presented every $24 \mathrm{~h}$. Drinking almost always occurred in a single bout at the beginning of the access period and terminated within $10 \mathrm{~min}$.

The schedule of access is expressed as the total time for one access and nonaccess period to be presented. For example, with the duration of the access period held constant at $20 \mathrm{~min}$, nonaccess periods of $70,160,340$, or 700 min generate schedules of access of $90,180,360$, and $720 \mathrm{~min}$.

The subjects, restricted to $80 \%$ of their ad-lib weight were first given unrestricted access to either $8 \%$ or $32 \%$ ethanol for 10 sessions. Access to water was unrestricted throughout the experiment. During the next 30 sessions, each subject was exposed to one of the following four restricted-access schedules: $90,180,360$, or $720 \mathrm{~min}$. That is, $16,8,4$, or 220 -min ethanol access periods were presented every $24 \mathrm{~h}$ (1,440 min). Following these 30 sessions of restricted access, unrestricted access was reinstated for 10 sessions. Thus, while different groups of animals were exposed to different access schedules, each subject was exposed to unrestricted access both before and after exposure to restricted access.

The results are presented in Figures 1 to 3, which show, respectively, the obtained changes in bout size, total con- 
sumption, and IBI, as a function of the schedule of access to ethanol. Values that differ significantly from those during the first period of unrestricted access are marked by an asterisk. Several points are apparent from the data. First, the amount consumed per bout increases when access to ethanol is restricted, and it decreases to baseline levels when unrestricted access is reintroduced (Figure 1). The increase occurred for all schedules of access used, and its size is positively related to the duration of the access schedule.

Changes in total daily consumption were not directly related to access schedule (Figure 2). In general, consumption increased across the three experimental conditions. During restricted access, decreases in consumption from the level observed during the prior period of unrestricted access were not noted until access to ethanol was limited to two 20-min access periods, per $24 \mathrm{~h}$. Restricting access also increased the IBI (Figure 3). Given the IBI obtained during unrestricted access, the increase was expected for the 360- and 720-min schedules but not for the $90-\mathrm{min}$ and $180-\mathrm{min}$ schedules. For example, the 90 min animals could have more than halved the IBI obtained during unrestricted access, had they responded during all the access periods. Yet only 3 of 32 animals showed even a slight decrease in IBI during restricted access.

The amount consumed per bout as well as the IBI were also a function of ethanol concentration. The amount consumed per bout (Figure 1) and the IBI (Figure 3) were greater for animals exposed to $32 \%$ ethanol. Concentration did not influence total consumption (Figure 2), because the increase in the amount consumed per bout at the higher concentration was offset by an increase in the IBI.

\section{Schedule of Access and Feeding Condition}

The results of the first experiment showed that control over the amount consumed per bout and the IBI by the ethanol access schedule and concentration was independent of total daily consumption. However, several questions remained. First, to what degree did the effect of restricting access on the amount consumed per bout depend on prior exposure to the 10 sessions of unrestricted access? Second, to what extent was the effect dependent upon food deprivation? Third, what changes in patterns of both water and ethanol consumption occur following prolonged exposure to the same schedule of ethanol access? For example, was the increase in consumption across the two unrestricted conditions of the first experiment dependent upon exposure to the intervening restricted-access condition, or would exposure only to unrestricted access for the same number of sessions have resulted in similar changes in consumption levels?

Figures 4 and 5 show the results of an experiment conducted to answer the above questions. Sixteen rats were divided into two groups and assigned to either an ad-lib or a food-deprivation condition. Half the animals in each deprivation group were exposed either to an unrestrictedor to a restricted-access schedule for $\mathbf{5 0}$ sessions. Ethanol concentration was $8 \%$, and water was always available.
Animals assigned to the restricted-access condition were presented with $20 \mathrm{~min}$ of access to ethanol every $160 \mathrm{~min}$, such that eight 20 -min access periods were presented every $24 \mathrm{~h}$.

Both the ad-lib and the food-deprived animals exposed to restricted access consumed more ethanol per bout than those exposed to unrestricted access. The effect, however, was much more dramatic for the food-deprived animals (Figure 4), and it was within the range of that observed

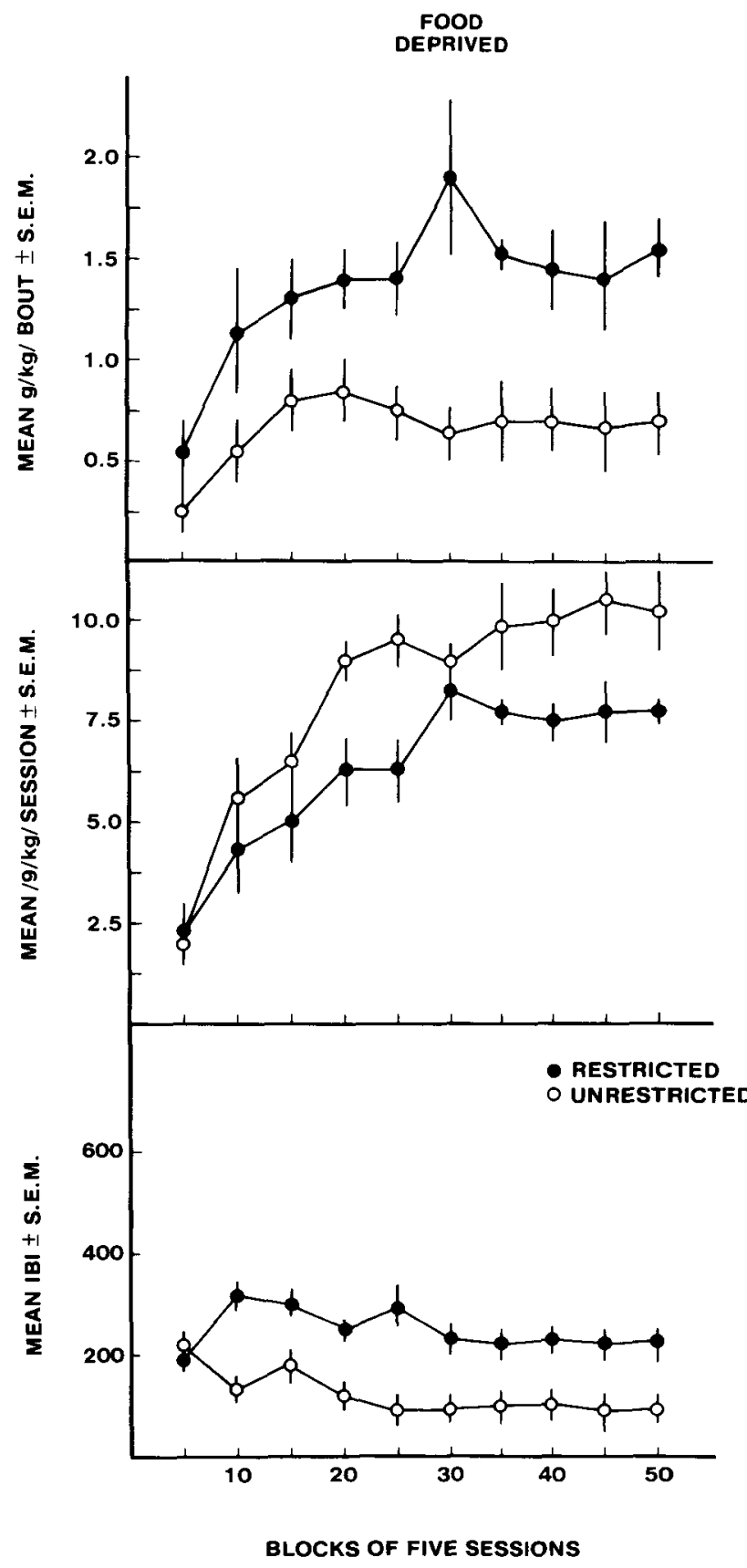

Figure 4. Mean g/kg/bout (top), g/kg/session (middle), and interbout interval (IBI; bottom) $\mathbf{S S E M}$ of food-deprived animals for restricted (closed circles) and unrestricted (open circles) access, plotted in blocks of five sessions. 

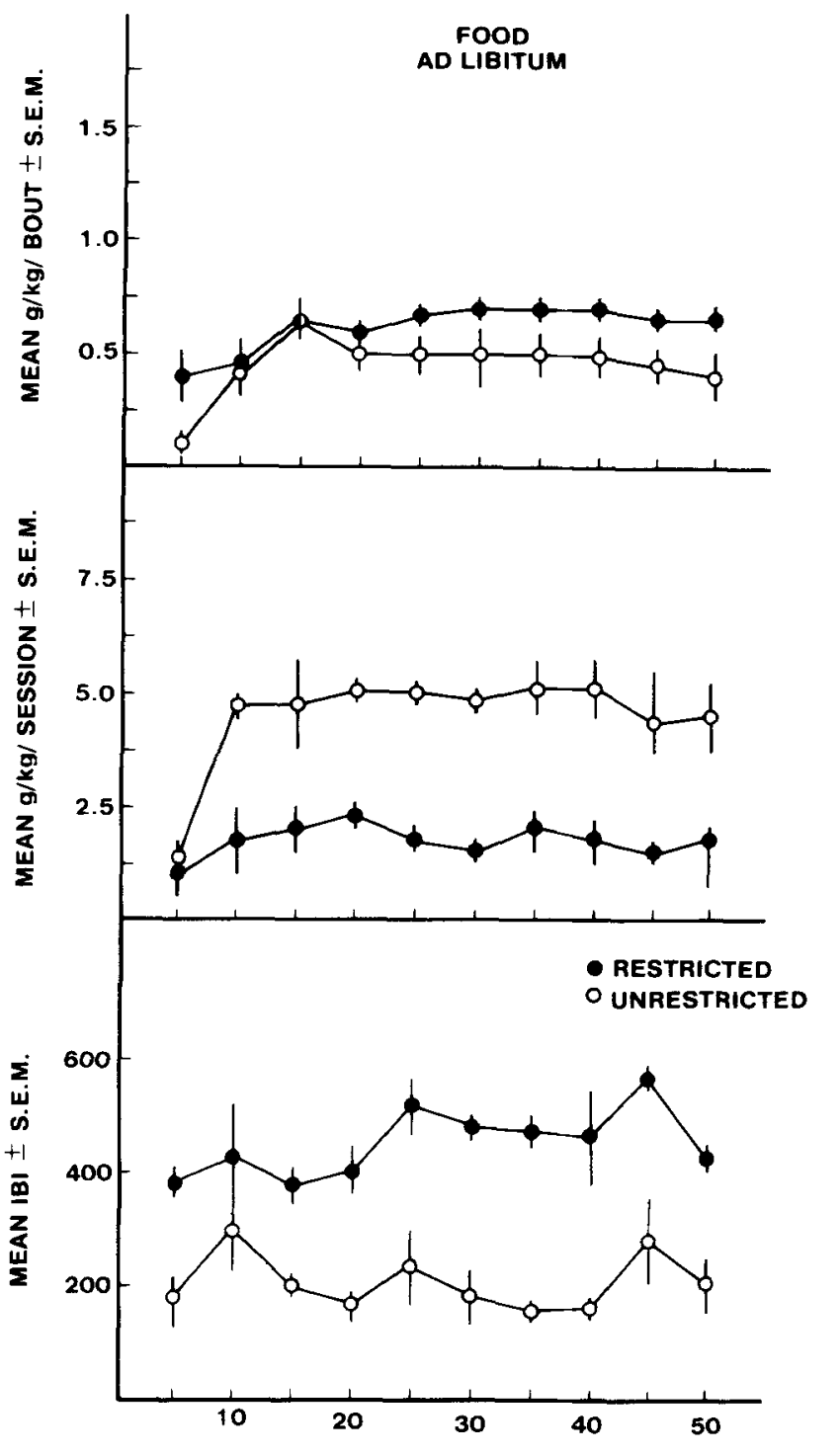

BLOCKS OF FIVE SESSIONS

Figure 5. Mean g/kg/bout (top), g/kg/session (middle), and interbout interval (IBI; bottom) \pm SEM of food-ad-lib animals during restricted (closed circles) and unrestricted (open circles) access, plotted in blocks of five sessions.

at the 180-min access-schedule value during the prior experiment. The difference in amount consumed per bout between restricted and unrestricted access appeared within 10 sessions and remained relatively constant throughout the experiment. As observed in the prior experiment, total daily consumption was greater during unrestricted access, regardless of deprivation level.

In addition to differences in ethanol consumption as a function of schedule of access, striking differences in patterns of both water and ethanol consumption were observed as a function of feeding condition. Figure 6 shows total fluid consumption together with ethanol consump- tion, in blocks of five sessions. Data from individual animals whose performance was representative are presented. Ethanol consumption of the food-deprived animals increased, but water consumption remained relatively constant. Ethanol consumption of the nondeprived animals also increased, but this was accompanied by a decrease in water consumption, so that total fluid consumption remained constant.

The temporal properties of water consumption also differed significantly for food-deprived and nondeprived animals (Figure 7). For the food-deprived animals, all water consumption occurred within the first $3 \mathrm{~h}$ of the session. In actuality, water consumption occurred only with food consumption. Data are plotted in 3-h blocks, because water data for animals on the restricted schedule were collected in 3-h intervals. However, the water responses of the animals on the unrestricted schedule were collected in 10-min intervals. These data, together with daily observation, confirmed that all food-deprived animals, regardless of access schedule, consumed all their daily water intake within $\mathbf{2 0}$ min of consuming their daily food ration. By contrast, the food-ad-lib animals consumed either little or no water (R1) or consumed considerable amounts of water throughout the session (R10).

The data of Figures 6 and 7 suggest that ethanol consumption serves different functions for food-deprived and nondeprived animals. For ad-libitum animals, ethanol consumption replaces water consumption and seems, like water consumption, to be dependent upon food consumption (Fitzsimmons \& LeMagnen, 1969; Kissileff, 1969; Normile \& Barraco, 1984). Although the temporal pattern of food consumption was not recorded, observation confirmed that most ethanol consumption occurred closely after food episodes. For the food-deprived animals, ethanol consumption developed independently of water consumption and food consumption. Food consumption continued to control water consumption throughout the experiment. An analysis of responding to ethanol in the access period presented concurrently with food (Figure 8) demonstrated that for food-deprived animals ethanol consumption did not occur when food was present.

The differences in fluid consumption patterns may suggest a possible explanation for the small effect of access schedule on amount consumed per bout by the ad-libitum animals (Figure 5). Either restricted-access schedules have different effects on food- and water-based responding, or the shift from responding to water to responding to ethanol may have interacted with the access schedule and attenuated its effect on the amount consumed per bout. The number of sessions required for this transfer may also be dependent upon ethanol concentration. In any event, it appears that extended exposure to ethanol is not a static process, and that perhaps different effects of restricted access would be obtained if access to ethanol were restricted after the transition from responding to water to responding to ethanol.

These differences in patterns of responding to ethanol and to water that are a function of differences in feeding 
UNRESTRICTED ACCESS

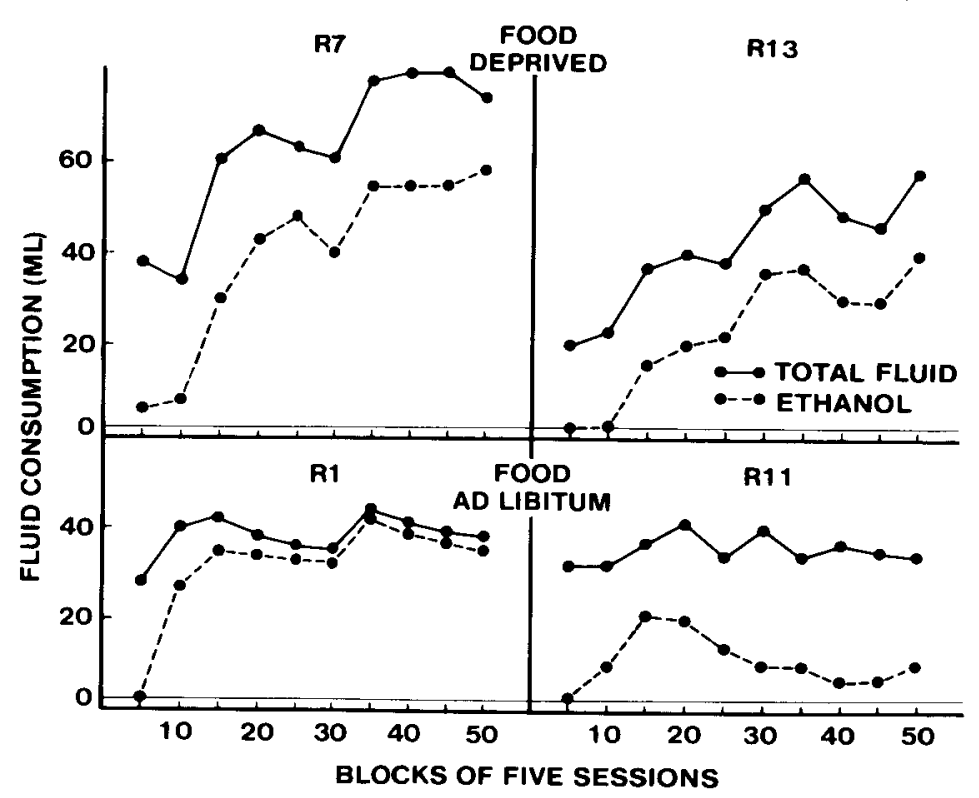

Figure 6. Total fluid and ethanol consumption of a respresentative animal of each experimental condition, plotted in blocks of five sessions.

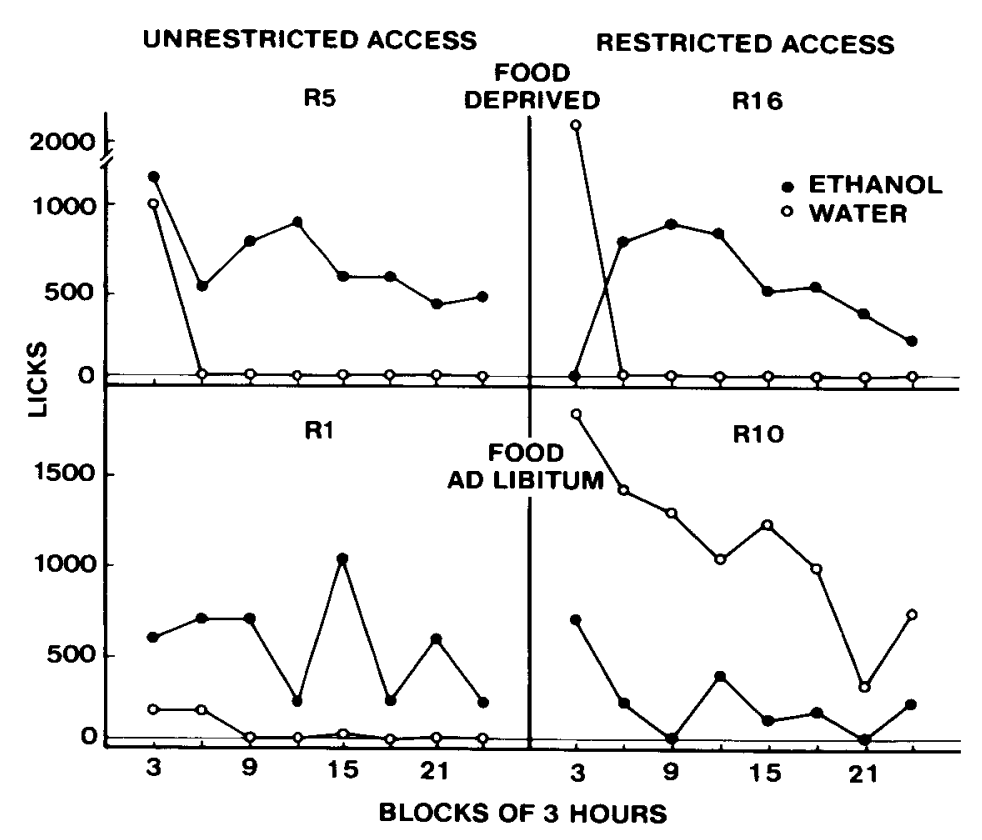

Figure 7. Mean number of licks for ethanol and water, plotted in 3-h blocks. Data are averaged over the last five sessions of the experiment.

condition have direct relevance for several procedures used to measure the effectiveness of ethanol as a drug. The behavior of animals consuming ethanol when some other substance is also available has been considered analogous to that of human alcohol consumers. The ratio of ethanol consumption to total fluid consumption is one of the earliest measures of the animals' preference for ethanol (Richter \& Campbell, 1940). Such preference studies have been criticized because high blood alcohol levels assumed to be present in human alcoholism are not present in the animals (Cicero, 1979). According to the present data, however, the problem is more fundamental. First, the ratio may be measuring different phenomena in food-deprived and nondeprived animals. In nondeprived animals, it measures the degree to which ethanol replaces water; in deprived animals, it measures the increase in ethanol consumption relative to a constant amount of water consumption. Consequently, the preference measure will be lower for food-deprived animals when both groups consume equal amounts of ethanol. More importantly, the 


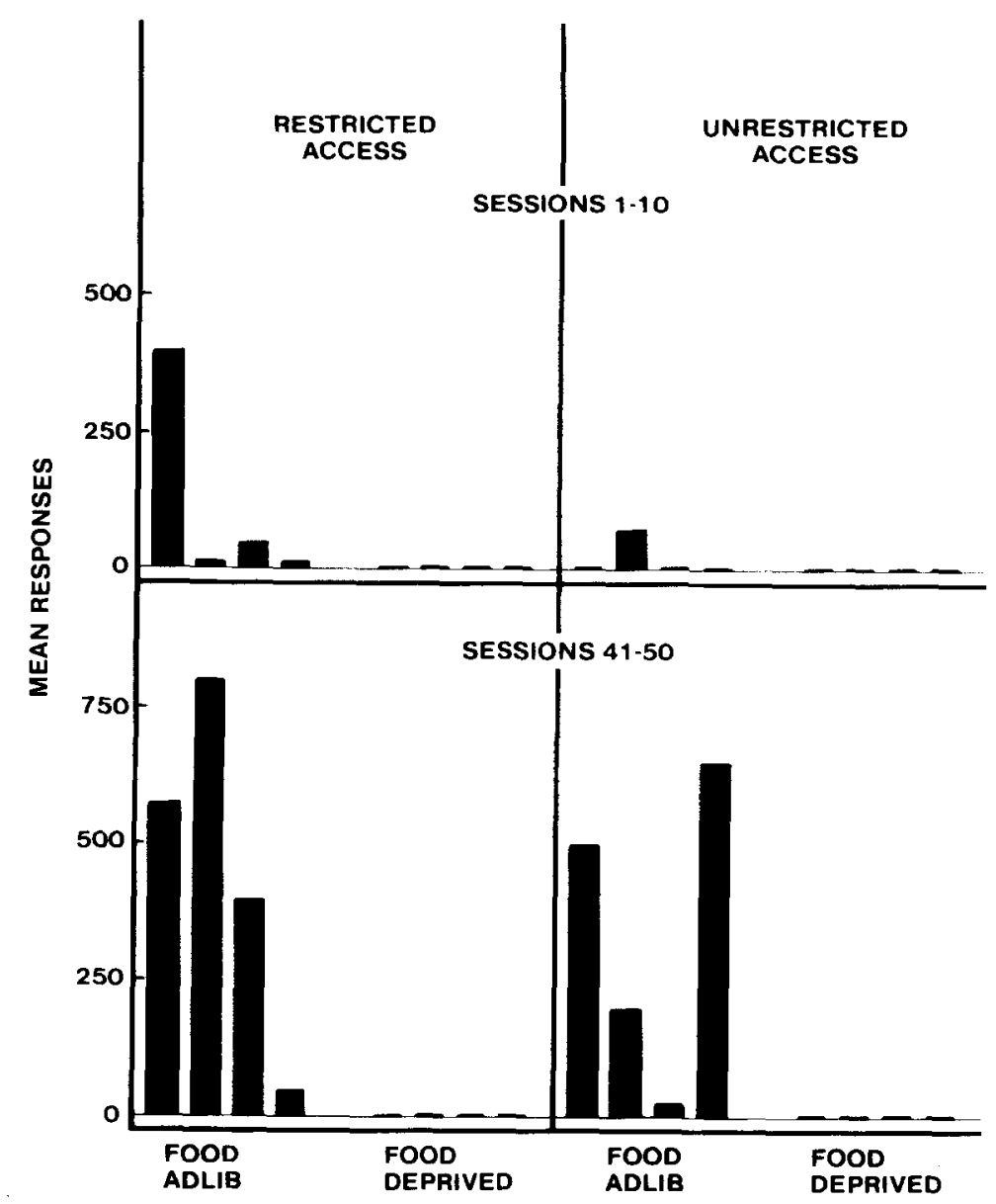

Figure 8. Mean number of responses to ethanol (licks) during the first $20 \mathrm{~min}$ of ethanol access per sexsion for food-deprived and food-ad-lib animals. Mean data are presented for the first five (top) and last five sessions (bottom).

ratio seems to be measuring different processes in fooddeprived and nondeprived animals.

The present data are also relevant to Carroll and Meisch's (1979) measure of the reinforcing effectiveness of an orally consumed pharmacological agent. They proposed that in order to be judged a reinforcer, a pharmacological agent should sustain a higher response rate than its delivery medium. However, in studies of oral selfadministration of ethanol, because the medium is usually water, problems may arise because of the relation between food and water consumption. The present data suggest that the outcome of this test is a function of whether food is present. If food were consumed, nondeprived animals would consume ethanol, not water, while food-deprived animals would consume water. With food absent, fooddeprived animals would consume ethanol, while nondeprived animals would either continue to consume ethanol or not consume either fluid.

The relation between feeding condition and ethanol consumption may also help explain the discrepancy in the reported difficulty in establishing ethanol consumption in polydipsia procedures when both water and ethanol are present early in training (Freed, 1974; McMillan \& Leander, 1978; Tang \& Falk, 1977). If consumption of water versus consumption of ethanol is partly a function of food deprivation, then differences in experimental outcomes may also be a function of the level of food deprivation.

\section{Proximity of Ethanol Access Periods to Each Other and to Food Delivery}

Within-session analyses of the pattern of responding to ethanol suggested that the temporal relation of access periods to food delivery and to other ethanol access periods was important in predicting the amount consumed per bout. First, food-deprived animals rarely consumed ethanol when it was presented concurrently with food. Secondly, the amount of responding in one ethanol access period was related to the amount of ethanol responding in adjacent ethanol access periods. For example, statistically significant negative lag 1 autocorrelations were obtained for all food-deprived, restricted-access subjects and for 2 of the 3 food-ad-lib subjects. Thus, if consumption occurred in one access period, it was likely to 

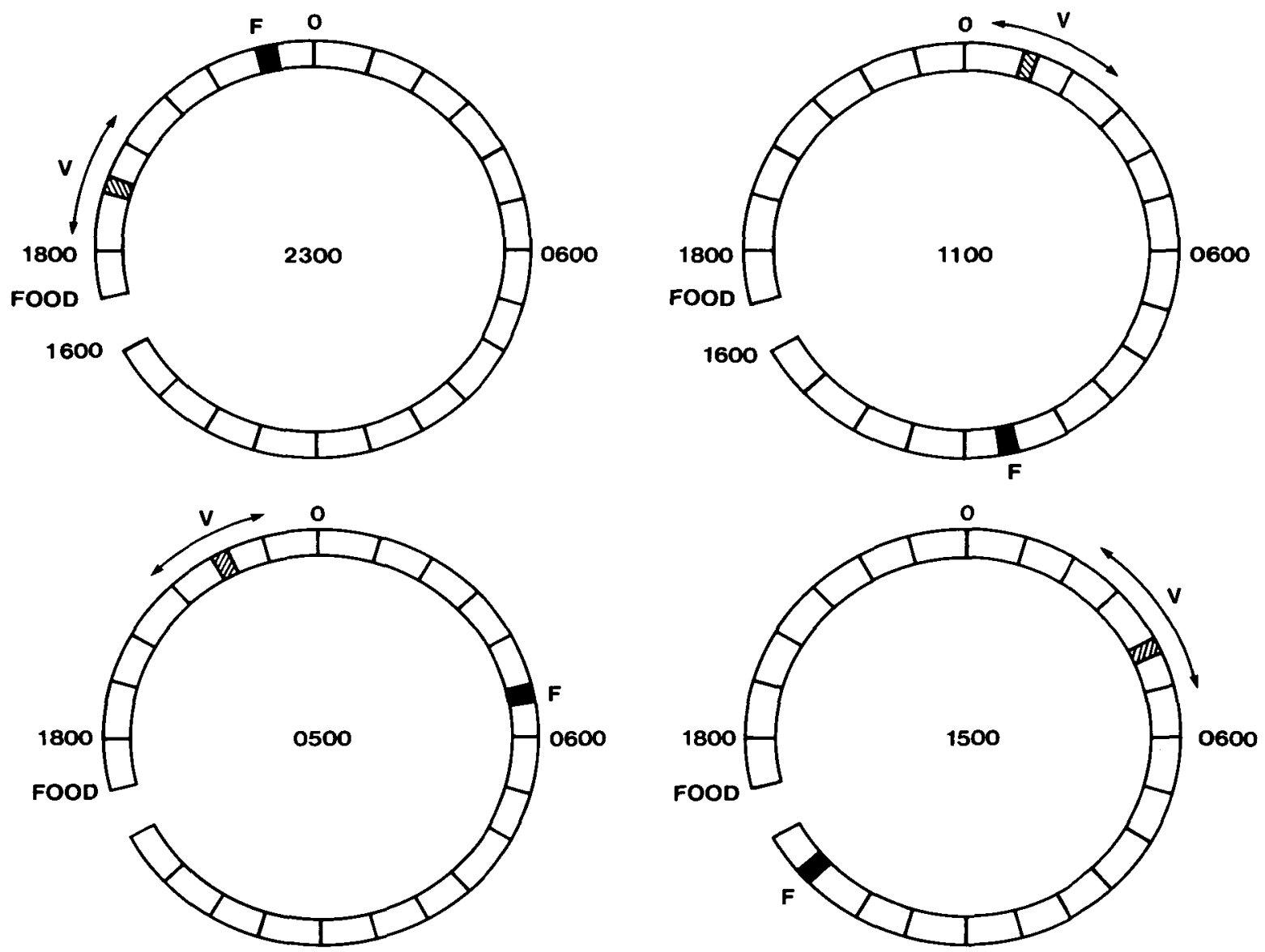

Figure 9. Schematic diagrams of the experimental conditions, showing the temporal location of the fixed access period (F), and food delivery as well as the session length. The arrows by the variable access period $(V)$ are included to emphasize that the variable access period was systematically varied across conditions for each of the four anchor groups.

be low in the next access period. The greater the amount consumed in an access period, the greater the likelihood of no responding to ethanol in the next scheduled access period.

These data suggested that the temporal location of access periods in relation to food delivery and to each other may influence the amount consumed per ethanol bout. To test this possibility, the following experiment was conducted. Sixteen animals were deprived of food to $80 \%$ of their ad-lib weight, and after 10 sessions of unrestricted access to $8 \%$ ethanol they were exposed to the 720 -min access schedule. Every 12 h the subjects were presented with $20 \mathrm{~min}$ of access and $700 \mathrm{~min}$ of no access. One of the two access periods presented per day was fixed in time throughout the experiment at $2300,0500,1100$, or $1500 \mathrm{~h}$. The other access period was changed every 10 sessions in an ascending and descending sequence. The procedure is schematically described in Figure 9 by four clock faces for each of the four anchor, or fixed, access periods (F) used. Food was presented at $1700 \mathrm{~h}$, the beginning of each session. The variable access period (V) was first presented at $1900 \mathrm{~h}$; then it was changed every 10 sessions to a time $3 \mathrm{~h}$ later. Following 10 sessions at
$1300 \mathrm{~h}$, the variable access period was presented earlier at selected times in order to redetermine selected points.

The 720-min schedule was chosen in order to determine whether the amount consumed per bout observed at this value in Experiment 1 could be replicated when ethanol was consumed in both bouts. In Experiment 1, no ethanol was consumed during the access period presented concurrently with food. Consequently, the obtained schedule was $1,440 \mathrm{~min}$, not $720 \mathrm{~min}$, in duration. It was not clear whether the amount consumed per bout would be the same when responding occurred in both access periods.

Figure 10 shows mean amount consumed per bout, during both fixed (closed circles) and variable access periods, plotted as a function of the time of presentation of the variable access period. It is important to remember that the fixed period was always presented at the same time. The thin vertical line represents the temporal location of the fixed period. Performances of representative animals are presented.

The amount consumed per bout is a function of the proximity of the other access period. When separated by $3 \mathrm{~h}$ or less, consumption in the first access period sup- 


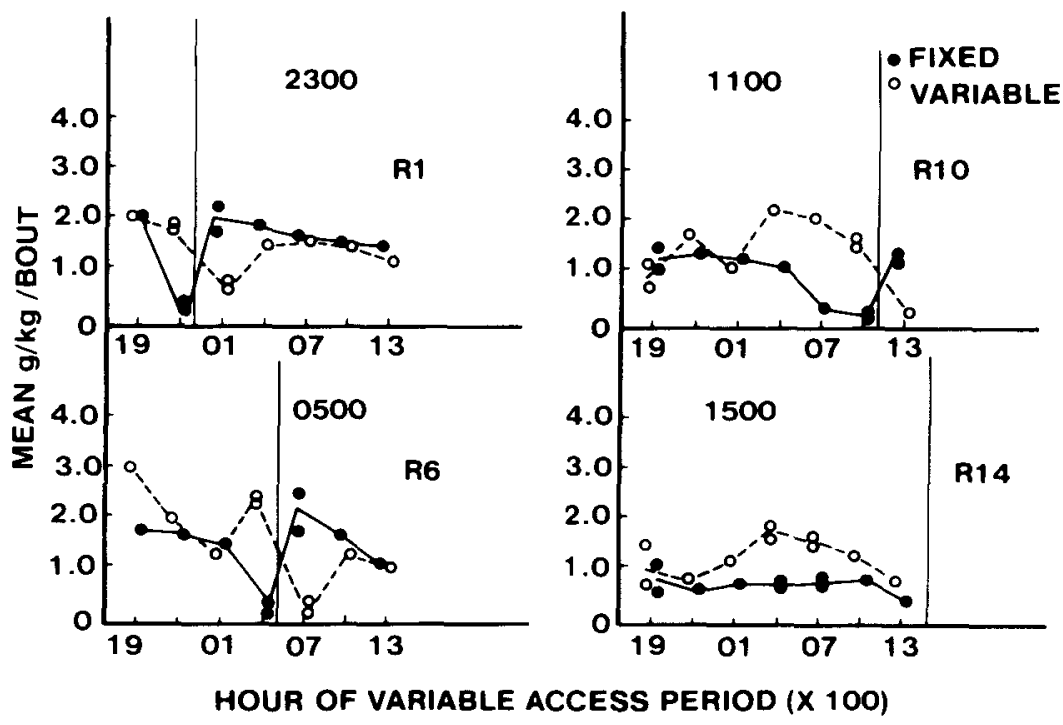

Figure 10. Mean g/kg/bout for both the fixed access period (closed circles) and variable access period (open circles) for representative subjects, as a function of the temporal location of the variable access period. Of the two access periods plotted at each temporal location, the one presented first in a particular condition, whether the variable or the fixed, is plotted slightly to the left of the other.

pressed responding during the second. Maximum consumption during both access periods was best predicted by the amount of time since the presentation of the other access period and not by the amount of time since food delivery. The amount consumed per bout could be affected by either the proximity to food delivery or to the other access period. Data presented earlier (Figure 8) showed that food delivery totally suppressed ethanol responding in a simultaneous access period. However, in this study, where the minimum time since food delivery equaled $3 \mathrm{~h}$, all but 2 animals consumed the most ethanol when the ethanol access periods were maximally separated, even when maximum separation placed one of the access periods within $3 \mathrm{~h}$ of food delivery. Finally, the later in the session the fixed access period was presented, the lesser the amount of ethanol consumed per access period.

\section{PREDICTING AMOUNT CONSUMED PER BOUT FROM FREQUENCY OF ACCESS}

The amount of ethanol consumed per bout was inversely related to the frequency of access periods. Figure 11 shows the logarithm (base 10) of the amount of ethanol consumed per bout $(\mathrm{g} / \mathrm{kg})$ as a function of the logarithm of the number of access periods presented per day. The data of the food-deprived animals given access to $8 \%$ ethanol in all the experiments are included in Figure 11. For purposes of analysis, several assumptions were made. First, unrestricted access was considered to be an access schedule. It differs from the other values used in these experiments in that it represents one of the two extreme values (i.e., an access schedule in which a 20 -min access period is presented every $20 \mathrm{~min}$ ). Second, the 720-min schedule in the first experiment was assigned a value of 1,440 (i.e., because animals in this condition never responded in the access period presented concurrently with food, they were considered to have been presented with only one access period per day). Third, the data points for the 720-min schedule value were taken from the condition of Experiment 3, in which the fixed access period was presented at $0500 \mathrm{~h}$ and the variable at the maximal temporal distance $(1900 \mathrm{~h})$.

A least squares line of best fit was calculated for the data. The regression line, regression equation, and the percentage of data variance accounted for are also presented in Figure 11.

\section{CONCLUSIONS}

The ethanol access schedule can be used to alter the amount and distribution of responding to ethanol within a daily session. The data support the position that excessive ethanol consumption will be understood when the relation between drinking and the environmental variables of which it is a function is understood.

Alcohol abuse is a behavioral problem defined by the observation that the organism drinks excessively. Current explanations of alcohol abuse focus on a variety of possible causes, such as intrapsychic conflicts, pharmacological effects, and genetic predispositions, rather than on the drinking response. The lack of information about the relation between excessive ethanol consumption and drinking as an adaptive behavioral system is surprising. While environmental variables related to the drinking system, 


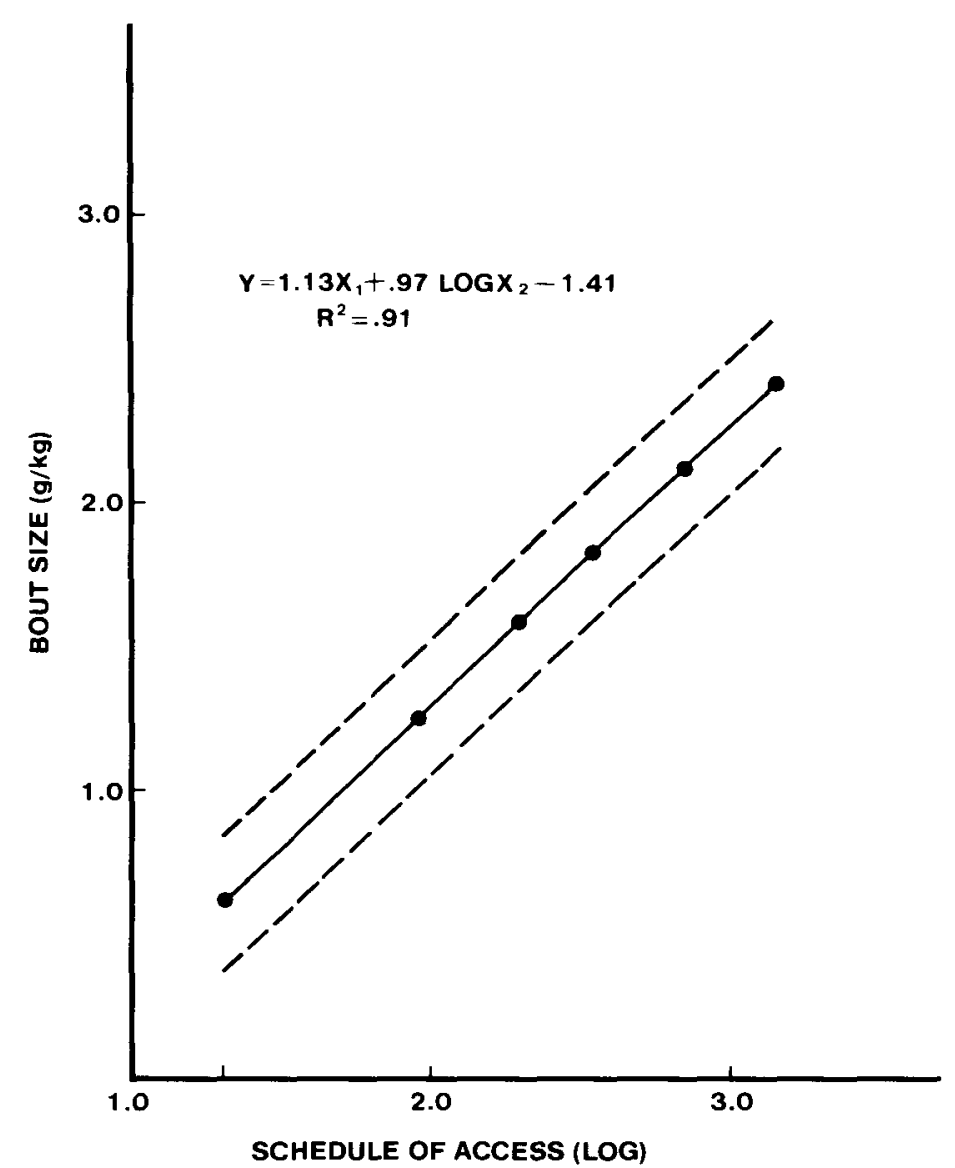

Figure 11. Mean $\mathrm{g} / \mathrm{kg} /$ bout as a function of the number of the number of 20-min ethanol access periods presented per day.

such as access schedule, may not be sufficient to induce excessive drinking in the absence of other controlling variables, they may work in conjunction with these other variables and may be necessary determiners of the development of physical dependence. For example, Samson and Falk (1975) have suggested that patterns of ethanol consumption are an important determiner of high bloodalcohol levels believed necessary for the development of dependence. Patterning of drug intake has also been stressed as important in dependence liability of drugs other than ethanol (Yanagita, 1976).

The effects of restricted access to ethanol may be only one aspect of the more general phenomenon of increased responding following periods of response restriction. Depriving an organism of the opportunity to emit a response will increase the probability of that response. The effect is not limited to alcohol, or even consumable substances, but includes socializing (Sloane \& Latane, 1974), wheel running (Premack, 1962) lever pressing (Premack \& Bahwell, 1959), and sexual activity (Beach \& Jordan, 1956). There is also considerble evidence that restricted access alters drug-intake patterns in humans. For example, when human patients were given the op- portunity to self-regulate their drug intake, they selfadministered less d-amphetamine (Bigelow, Liebson, Kaliszak, \& Griffiths, 1978), morphine or merperidine (Sechzer, 1971), diazepam (Winstead, Anderson, Eilers, Blackwell, \& Zaremba, 1974), or propoxyphene (Winstead, Parker, \& Willi, 1977) than would have been administered according to schedules determined by physicians. The results are generally interpreted mentalistically. For example, Winstead et al. (1977) state that "perhaps giving the patient some degree of autonomy and control in his treatment alleviates anxiety that might break through the threshold to cause the patient to perceive pain" (p. 1466). A much simpler and more general explanation is that the changes in drug consumption of these patients show the effect of going from conditions of restricted to unrestricted access.

Similar influences may be involved in studies that examine the effect of a work requirement on patterns of alcohol consumption (Mello \& Mendelson, 1978). During free access to ethanol, moderate amounts of ethanol were consumed at a relatively constant rate. When a response requirement was introduced, the pattern of consumption changed to one in which periods of drinking leading to 
intoxication were interspersed with periods of abstinence. If the introduction of a work requirement is in effect an alternate means of restricting access, then these results may also reflect the influence of going from conditions of less restricted to conditions of more restricted access.

\section{REFERENCES}

Altshuler, H. L. (1980). Intragastric self-administration of ethanol: A subhuman primate model of alcoholism. In K. Eriksson, J. D. Sinclair, and K. Kiianmaa (Eds.), Animal models in alcohol research (pp. 179-183). London: Academic Press.

Altshuler, H. L., \& PHilluPs, P. E. (1978). Intragastric selfadministration. In B. T. Ho, D. W. Richards, \& D. L. Chite (Eds.), Drug discrimination and state-dependent learning (pp. 263-282). New York: Academic Press.

Altshuler, H., Weaver, S., \& Phillips, P. (1975). Intragastric selfadministration of psychoactive drugs by the rhesus monkey. Life Sciences, 17, 883-890.

Amit, Z., STERN, M. H., \& WISE, R. A. (1970). Alcohol preference in the laboratory rat induced by hypothalamic stimulation. Psychopharmacologia, 19, 367-377.

BEACH, F. A., JoRdAN, L. (1956). Sexual exhaustion and recovery in the maie rat. Quarterly Journal of Experimental Psychology, 8 , 121-133.

Bigelow, G. E., Lienson, I., Kaliszak, J., \& Griffiths, R. R. (1978). Therapeutic self-medication as a context for a drug abuse research. In N. A. Krasnegor (Ed.), Self-administration of abused substances: Methods for study (pp. 44-58). NIDA Research Monograph 20. Rockville, MD: Supt. of Docs., U.S. Government Printing Office.

CARroll, M. E., MEISCH, R. A. (1979). Concurrent etonitazene and water intake in rats: Role of olfaction and auditory stimuli. Psychopharmacology, 64, 1-7.

Cicero, T. J. (1979). Animal analogues of alcoholism. In E. Majchrowicz \& E. P. Noble (Eds.), Biochemistry and pharmacology of ethanol (Vol. 2, pp. 533-560). New York. Plenum Press.

Collier, G. , Hirsch, E., \& Hamlin, P. (1972). The ecological determinants of reinforcement in the rat. Physiology \& Behavior, 9, 705-716.

FALK, J. L. (1961). Production of polydipsia in normal rats by an intermittent food schedule. Science, 133, 195-196.

FALK, J. L. (1966a). The motivational properties of schedule-induced polydipsia. Journal of the Experimental Analysis of Behavior, 9, 19-25.

FALK, J. L. (1966b). Schedule-induced polydipsia as a function of fixed interval length. Journal of the Experimental Analysis of Behavior, 9 , 37-39.

FALK, J. L. (1967). Control of schedule-induced polydipsia: Type, size and spacing of meals. Journal of the Experimental Analysis of Behavior, 10, 199-206.

FAlK, J. L., SAmSON, H. H., \& WINGER, G. (1972). Behavioral maintenance of high concentrations of blood ethanol and physical dependence in the rat. Science, 177, 811-813.

Fitzsimmons, J. T., LeMagnen, J. (1969). Eating as a regulatory control of drinking in the rat. Joumal of Comparative \& Physiological Psychology, 67, 273-283.

FREED, E. X. (1974). Fluid selection by rats during schedule-induced polydipsia. Quarterly Journal of Studies on Alcohol, 35, 1035-1043.

HALPERN, B. P. (1977). Functional autonomy of the tongue and mouth of mammals. In J. A. W. M. Weijnen \& J. Mendelson (Eds.), Drinking behavior oral stimulation reinforcement and preference (pp. 192). New York: Plenum Press.

KISSILEFF, H. R. (1969). Food-associated drinking in the rat. Journal of Comparative \& Physiological Psychology, 67, 284-300.

LeMAGNen, J. (1960). A study of some factors associated with the changes in ethyl alcohol consumption in rats. Journal de Physiologie, 52, 873-884.

LESTER, D. (1966). Self-selection of alcohol by animals, human variation, and the etiology of alcoholism: A critical review. Quarterly Journal of Studies on Alcohol, 27, 395-438.
Lester, D., Freed, E. X. (1973). Criteria for an animal model of alcoholism. Pharmacology, Biochemistry \& Behavior, 1, 103-107. MacDonall, J. S., \& Marcucella, H. (1979). Increasing the reinforcing effectiveness of ethanol. Pharmacology, Biochemistry \& Behavior, 10, $211-216$.

Marcucella, H., MacDonall, J. S., \& Munro, I. (1981). Ethanol consumption as a function of limited availability, ethanol concentration and food deprivation. Alcoholism: Clinical and Experimental Research, 5(1), 35.

Marcucella, H., Munro, I., MacDonall, J. S. (1984), Patterns of ethanol consumption as a function of the schedule of ethanol availability. Joumal of Pharmacology \& Experimental Therapeutics, 230, 658-664.

MARDONES, J. (1960). Experimentally induced changes in the free selection of ethanol. International Review of Neurobiology, 2, 41-76.

Marwine, A., Collier, G. (1979). The rat at the waterhole. Journal of Comparative \& Physiological Psychology, 93, 391.402.

MCMillan, D. E. , LeANDER, J. D. (1978). Food, water and ethanol consumption by rats under a fixed interval schedule of food presentation. Drug \& Alcohol Dependence, 3, 227-234.

MEISCH, R. A. (1977). Ethanol self-administration: Infrahuman studies In T. Thompson \& P. B. Dews (Eds.), Advances in behavioral pharmacology (pp. 35-84). New York: Academic Press.

MELLo, N. K. (1973). A review of methods to induce alcohol addic tion in animals. Pharmacology, Biochemistry \& Behavior, 1, 89-101

Mello, N. K., \& Mendelson, J. H. (1978). Marihuana, alcohol and polydrug use: Human self-administration studies. In M. Krasnegor (Ed.), Self-administration of abused substances: Methods for study (pp. 93-127). NIDA Research Monograph 20. Rockville, MD: Supt of Docs., U.S. Government Printing Office.

Myers, R. D., \& Veale, W. L. (1972). The determinants of alcohol preference in animals. In B. Kissin \& H. Begleiter (Eds.), The biol ogy of alcoholism: Vol 2. Physiology and behavior (pp.131-168). New York: Plenum Press.

Normile, H. J., \&ARRACo, R. A. (1984). Relation between food and water intake in the pigeon. Journal of Comparative Psychology, 98 , 76-90.

Pinel, J. P. J., \& Huang, E. (1976). Effects of periodic withdrawal on ethanol and saccharin selection in rats. Physiology \& Behavior. 16, 693-698.

Premack, D. (1962). Reversibility of the reinforcement relation. Science, 16, 255-257.

Premack, D. Bahwell, R. (1959). Operant lever pressing by a monkey as a function of interest level. Journal of the Experimental Anal. ysis of Behavior, 2, 127-131.

Richter, C. P., CAmpBell, K. (1940). Alcohol taste thresholds and concentration of solutions preferred by rats. Science, 91, 507.

SAmson, H. H., FAlK, J. H. (1975). Pattern of daily blood ethanol elevation and the development of physical dependence. Pharmacology, Biochemistry \& Behavior, 3, 1119-1123.

SECHZER, P. H. (1971). Studies in pain with the analgesis demand sys tem. Anesthesia \& Analgesia, 50, 1-10.

SINCLAIR, J. D., Bender, D. O. (1979). Limited increases in alcohol intake by rats produced by infrequent periodic access. Journal of Studies on Alcohol, 40, 729-731.

SINCLAIR, J. D., \&ENTER, R. J. (1967). Increased preference for ethanol in rats following alcohol deprivation. Psychonomic Science, 8, 11-12.

Sinclair, J. D., Senter, R. J. (1968). Development of an alcohol deprivation effect in rats. Quarterly Jourmal of Studies on Alcohol, 28, 863-867.

SloANe, J. R., LATANE, B. (1974). Social deprivation and stimulus satiation in the albino rat. Journal of Comparative \& Physiological Psychology, 87, 1148-1156.

TAglaferRo, A. R., Levitsky, D. A. (1982). Overcompensation of food intake following brief periods of food restriction. Physiology \& Behavior, 29, 747-750.

TANG, M., FALK, J. L. (1977). Ethanol dependence as a determinant of fluid preference. Pharmacology, Biochemistry \& Behavior, 7, 471-474.

VEALE, W. L., MYERS, R. D. (1969). Increased alcohol preference in rats following repeated exposures to alcohol. Psychopharmacologia, 15, 361-372. 
WAlLGRen, H., BARRY, H. (1970). Actions of alcohol: Vol 2. Chronic and clinical aspects. New York: Elsevier.

WAYNER, M. J., \& GreENBERG, I. (1972). Effects of hypothalamic stimulation, acclimation, and periodic withdrawal on ethanol consumption. Physiology \& Behavior, 9, 737-740.

Wayner, M. J., Greenberg, I., Carey, R. J., \& Nolley, D. (1971). Ethanol drinking elicited during electrical stimulation of the lateral hypothalamus. Physiology \& Behavior, 7, 793-795.

Wayner, M. J., Greenberg, I., Tartaglione, R., Nolley, D., Fraley, S., \& Cotr, A. (1972). A new factor affecting the consumption of ethyl alcohol and other sapid fluids. Physiology \& Behavior, 8, 345-362.

Weunen, A. W. M., Mendelson, J. (Eds.) (1978). Drinking behavior: Oral stimulation, reinforcement, and preference. New York: Plenum.
Winstead, D. K., Anderson, A., Eilers, M. K., Blackwell, B., 2 ZAREMBa, A. L. (1974). Diazepam on demand. Archives of General Psychiatry, 30, 349-351.

Winstead, D. K., Parker, M., \&ilu, F. J. P. (1977). Propoxyphene on demand. Archives of General Psychiatry, 34, 1463-1468.

WISE, R. A. (1973). Voluntary ethanol intake in rats following exposure to ethanol on various schedules. Psychopharmacologia, 29, 203-210.

YANAGITA, T. (1976). Some methodological problems in assessing dependence-producing properties of drugs in animals. Pharmacological Review, 27, 503-509.

(Manuscript received February 24, 1986; revision accepted for publication June 17,1987 .) 